\title{
Operational experience and modelling of biomass combustion process in cogeneration systems with ORC units
}

\author{
Jacek Kalina ${ }^{1,{ }^{*}}$, Andrzej Sachajdak ${ }^{1}$, Rafat Strzałka ${ }^{2}$, Mateusz Świerzewski ${ }^{1}$, Jerzy Ć więka ${ }^{3}$ \\ ${ }^{1}$ Institute of Thermal Technology, Silesian University of Technology, Poland \\ ${ }^{2}$ University of Applied Sciences Stuttgart, zafh.net, Germany \\ ${ }^{3}$ Krosno Municipal Holding, Heating Department, Poland
}

\begin{abstract}
Organic Rankine Cycle (ORC) technology is nowadays considered as interesting option for utilization of local biomass resources. The number of plants worldwide is constantly growing within typical range of electric power output form 0.2 to $3.0 \mathrm{MW}$. In such systems biomass combustion chambers with step or vibrating grates are used. Heat is transferred to the thermal oil in a separate spiral heat exchanger. The biggest problems in such system are variable and inaccurately predictable properties of biomass that directly influences operation of combustion equipment, and thus the performance of entire cogeneration plant. In this paper experiences from two plants are presented. The plants are located in Krosno (Poland) and in Ostfildern near Stuttgart, Germany. In the first one high quality wood chips are used whereas the second one is powered by low quality biomass with the mass ash content approaching $18 \%$. Although similar, both plants use different strategies to control the combustion process. Long term measurements are used to develop biomass combustion models in the plants. The paper also presents results of implementation of the online optic measurement system for monitoring of biomass properties such as LHV, ash and water content.
\end{abstract}

\section{Introduction}

Biomass is nowadays in Europe the most important source of primary renewable energy. In 2016 wood and other solid biofuels as well as renewable wastes represented a share of $49.4 \%$ of total 211 Mtoe of primary renewable energy production [1]. On the other hand it is still a challenge to effectively use locally available feedstock for electricity generation in small scale distributed plants. In practice the Organic Rankine Cycle (ORC) technology coupled to the biomass combustion is the only technology that is widely used. This solution nowadays is fully commercialised and represent relatively low technological risk, whereas other technologies, mainly based on gasification still suffer difficulties to take off in the market. Traditional steam plants are not economically viable at small scale and therefore are not frequently implemented in local energy systems. According to Tartière et al. $[2,3]$ the

\footnotetext{
*Corresponding author: jacek.kalina@polsl.pl
} 
cumulated installed capacity of the ORC plants in 2016 exceeded $2.7 \mathrm{GW}$ in more than 705 projects where 1754 ORC units have been deployed. The share of biomass fired plants is $11 \%$ with $301 \mathrm{MW}$ of the electric power installed in $332 \mathrm{ORC}$ units. The range of the installed electric power of a single plant is 0.2 to $13.0 \mathrm{MW}$, however majority of systems are below 1.5 MW. Small plants up to $0.5 \mathrm{MW}$ represent the biggest share of the total number of plants. Most of the plants were built within years 2004 to 2016 in Germany, Austria and Italy as the result of effective system of incentives and financial support for investment projects.

Biomass fired cogeneration systems based on the ORC technology are relatively simple, low pressure and modular solutions, typically running in fully automatic mode driven by the required heating power. The combined heat and power (CHP) blocs have been traditionally sized for either base or medium heating load of a district heating network. Remaining heat demand is covered by boilers of different types. The electric power results from the heat tracking operation and consequently it varies within the range of $20 \%-100 \%$ of the nominal power output. Fig. 1 presents typical block diagram of the entire heat and power system with biomass fired cogeneration block.

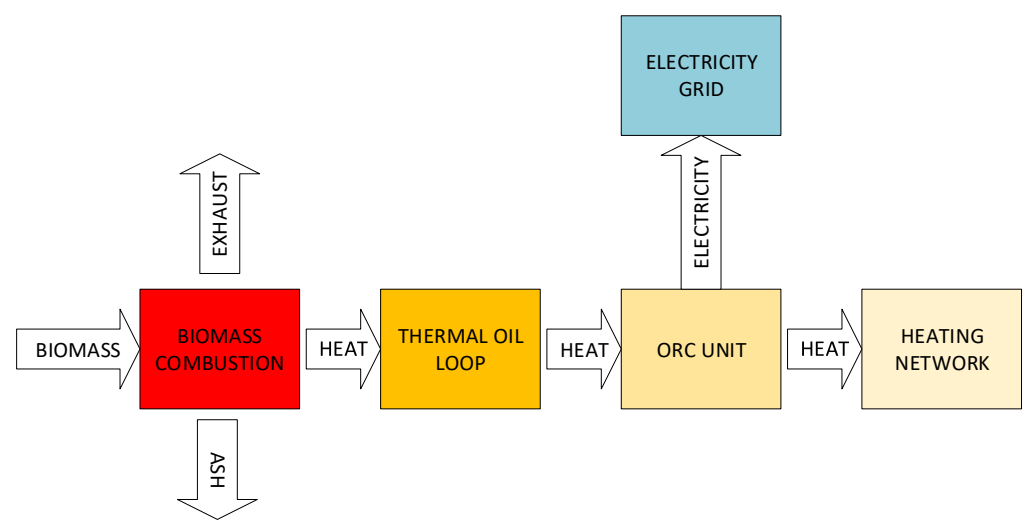

Fig. 1. Block diagram of biomass fired cogeneration plant with ORC unit.

In a typical system combustion of biomass takes place in a dedicated combustion chamber without heat transfer surfaces. The heat is transferred to thermal oil in separate heat exchangers placed outside the combustion section. The biggest problem of biomass fired cogeneration plants with ORC units is effective control of the combustion process. The control algorithm must assure set values of critical system parameters such as combustion temperature, ash temperature, thermal oil outlet temperature and at the same time it should flexibly react to volatile biomass properties and heat demand. Effective control of the combustion process becomes the most important issue at part load operation out of the heating season, when the cogeneration system is usually the only source of heat for preparation of sanitary hot water. Difficulties result from the fact that biomass mass flow rate and composition are known only approximately and vary in time on continuous basis. Estimated values are only within a limited range of accuracy. In addition the system is controlled using temperature and pressure signals what results in fluctuations of critical output signals.

Although, there is significant number of biomass fired cogeneration plants with ORC modules in operation, there are not many studies available in the literature that are related to the biomass combustion equipment performance. Strzałka et al. [5] developed mathematical model of the combustion process in a biomass furnace of the cogeneration plant with ORC technology. The model took into account different stages of biomass thermal decomposition and combustion that were modelled using energy balance equations. As the detailed information on chemistry and kinetics of processes was not available the authors introduced 
necessary simplifications and assumptions regarding model constants and heat transfer parameters. Prado et al. [6] presented research on energy performance of district heating CHP plants based on biomass boilers and ORC generators. Research covers several objects located in South Tyrol (Italy). Potential improvements of CHP plants connected to DH networks have been presented.

In this paper operation and performance of two biomass combustion systems of cogeneration plants with ORC units is discussed. The first system is municipal district heating cogeneration plant in Krosno (Poland) with the biomass boiler delivered by VAS Energy Systems International GmbH and the Turboden 14 CHP ORC unit. The plant has been in operation since 2013. The second system is the one in Ostfildern (Germany), that was presented earlier in $[4,5]$. The system has been in operation since 2004 and is now approaching mature exploitation period. Biomass combustion system for the plant was delivered by the $\mathrm{KCO}$ Cogeneration und Bioenergie $\mathrm{GmbH}$ while the ORC module was manufactured by the GET GmbH Gesellschaft für Energietechnik. In general the same technology has been implemented and both plants have similar power output. In both plants the ORC working fluid is octamethyltrisiloxane C8H24Si3O2 (short name: MDM, CAS No. 107-51-7). The heat between biomass combustion system and the ORC unit is transferred by thermal oil Therminol 66. There are also some specific differences including combustion process connected with different type of fuel. Technical specifications of both systems studied in this paper are presented in Tab. 1.

Table 1. Technical specification of ORC units.

\begin{tabular}{|l|c|c|c|}
\hline Quantity & \multirow{2}{*}{ Unit } & \multicolumn{2}{c|}{ Value } \\
\cline { 3 - 4 } & & Krosno (PL) & Ostfildern (DE) \\
\hline \multicolumn{3}{|c|}{ Thermal oil loop } \\
\hline Nominal temperature HT oil loop (in/out) & ${ }^{\circ} \mathrm{C}$ & $310 / 250$ & $300 * / 240$ \\
\hline Thermal power input HT loop & $\mathrm{kW}$ & 6130 & 6356 \\
\hline Nominal temperature LT oil loop (in/out) & ${ }^{\circ} \mathrm{C}$ & $250 / 130$ & - \\
\hline Thermal power input LT loop & $\mathrm{kW}$ & 585 & - \\
\hline Overall thermal input & $\mathrm{kW}$ & 6715 & 6356 \\
\hline \multicolumn{3}{|c|}{ Biomass combustion furnace } & 8000 \\
\hline Nominal thermal power & $\mathrm{kW}$ & 8529 & Wood chips \\
\hline Fuel type & - & Wood chips & Therminol 66 \\
\hline Heat transfer medium (thermal oil) & - & Therminol 66 & The \\
\hline Combustion gas outlet temperature & ${ }^{\circ} \mathrm{C}$ & 1013 & $950-1000$ \\
\hline Combustion air flow & $\mathrm{Nm}{ }^{3} / \mathrm{h}$ & 17558 & 20000 \\
\hline Indicative biomass consumption & $\mathrm{kg} / \mathrm{h}$ & 2935 & 3240 \\
\hline
\end{tabular}

*Due to safety reasons reduced to 290 in operation [4] 


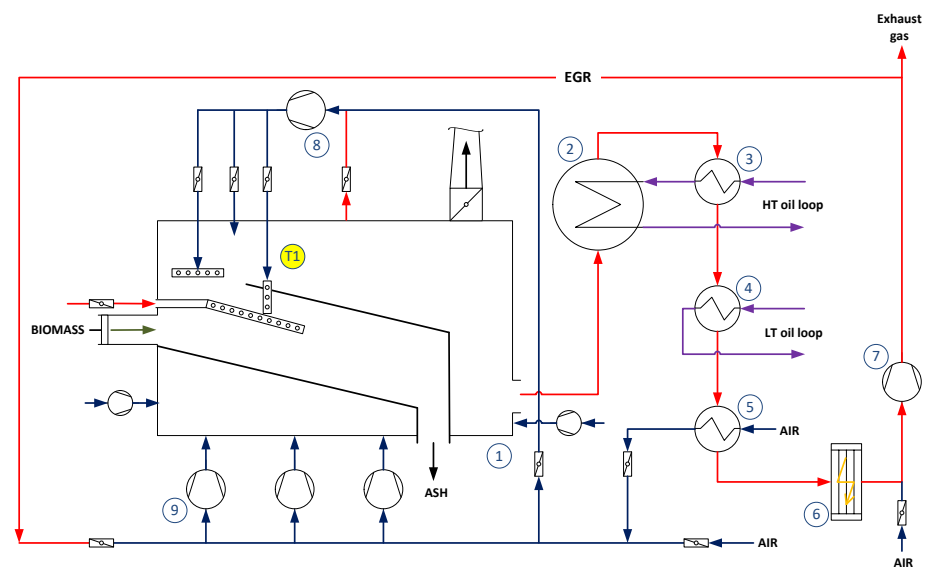

Fig. 2. Scheme of biomass combustion end heat exchanger system in Krosno (PL).

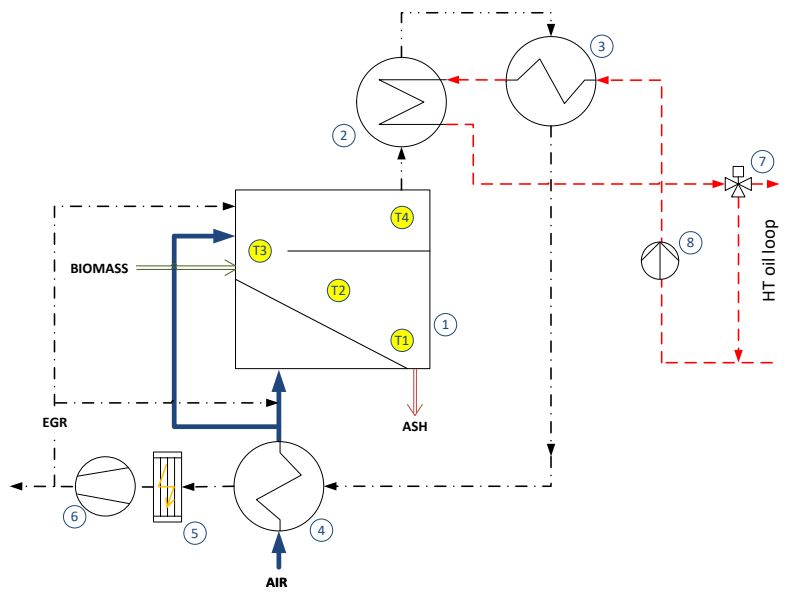

Fig. 3. Scheme of biomass combustion end heat exchanger system in Ostfildern (DE).

\section{Biomass combustion and heat exchange}

Typical grate combustion technology is implemented in analysed plants with ORC units. The entire combustion process takes place co-current in several stages, namely heating and drying, pyrolysis and char combustion. Into different sections of combustion chamber air and recirculated exhaust gas (EGR) are delivered $[5,7]$. There are several entry points of these gasses and appropriated distribution of air and EGR is one of the key issues of the control system. The main control parameters of the combustion system are flows of biomass, primary and secondary combustion air as well as primary and secondary exhaust gas recirculation. These parameters are varied in order to maintain desired values of heating power, combustion temperature, ash temperature and thermal oil outlet temperature. Control of the heating capacity is qualitative, i.e. the flow of Therminol 66 is constant while inlet and outlet temperatures vary with heating power.

Although the biomass fired cogeneration systems with ORC modules are of relatively simple structure establishing an effective control system of a plant is not a trivial problem. The difficulties are the result of variable external conditions such as heating network water flow, forward and return temperatures as well as feedstock characteristics including water 
content, and ash content and heating value. These independent parameters can change on continuous rate and together with system control algorithms can cause significant fluctuations of system output parameters and overall performance indices. In extreme, and fortunately rear, cases the system can lose its stability and goes off the grid. Figures 4 to 6 depict key parameters of the analysed biomass combustion system in form of annual characteristics. Points on the graphs represent measurements from various operational periods related to current heat output. It can be noted that both plants are controlled in a slightly different manner, Ostfildern objects reached more stable operation regime where in Krosno plant still is observed significant dispersion of these key parameter of plant operation.
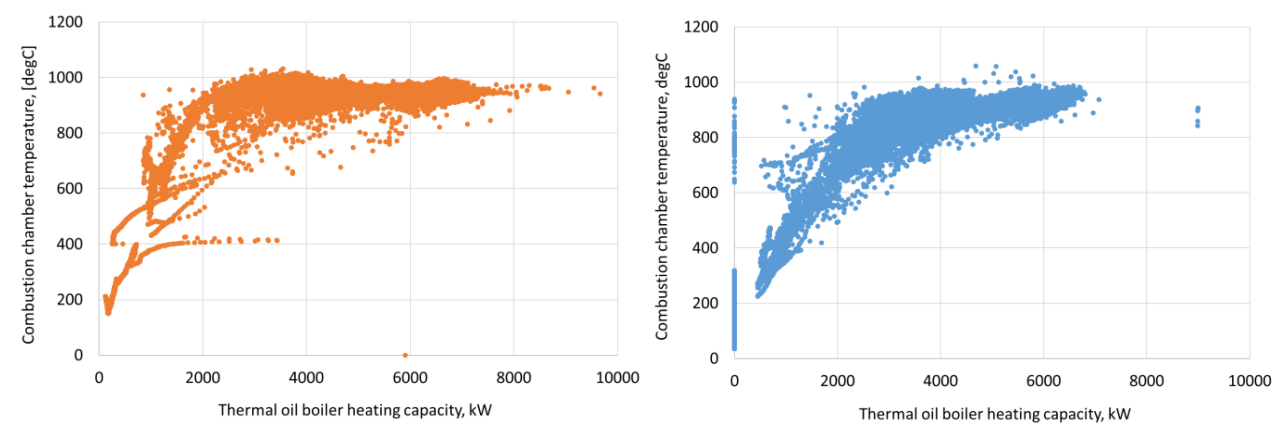

Fig. 4. Combustion chamber outlet temperature Texh; Krosno (left) Scharnhauser Park (right).
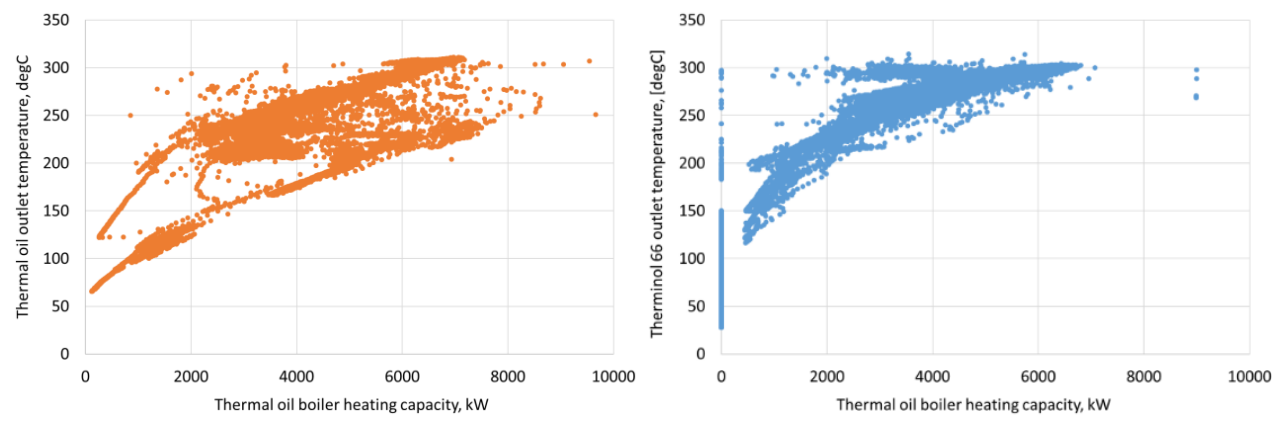

Fig. 5. Thermal oil outlet temperature; Krosno (left), Scharnhauser Park (right).
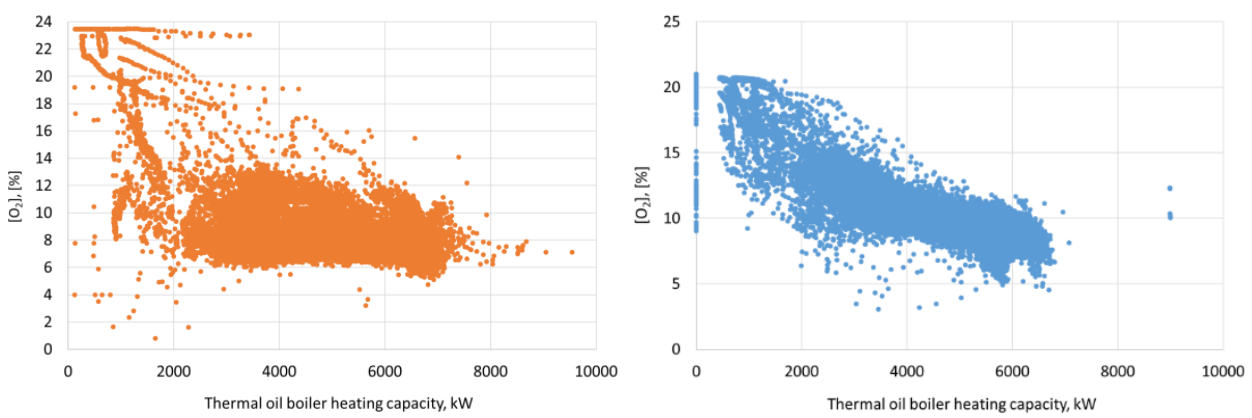

Fig. 6. Exhaust gas oxygen content; Krosno (left), Scharnhauser Park (right) 


\section{Fuel characteristics}

Important difference between the two systems is quality of the biomass feedstock used as fuel. In Ostfildern low quality biomass is used whereas in Krosno biomass parameters are maintained at much higher level. Fig. 7 presents pictures of the fuel used in both plants.
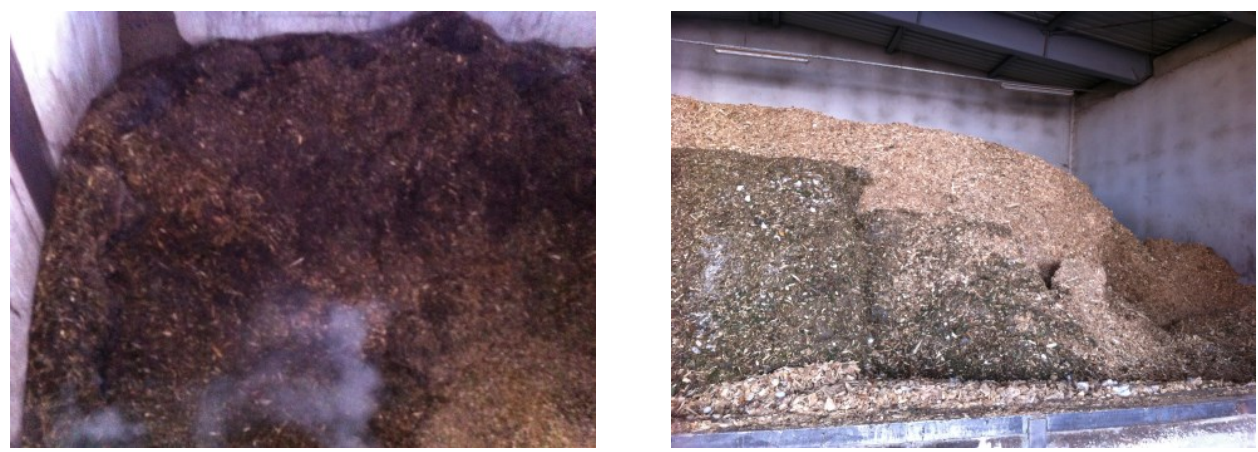

Fig. 7. Biomass fuel as received at Scharnhauser Park (left) and Krosno (right) plants.

Biomass fuels are extremely variable in terms of heating value, moisture content and ash content. However in typical system these parameters are measured only periodically. In the Krosno plant several samples of fuel are collected within each month and monthly average value of each parameter is determined. Results are presented in Fig. 8. Information in the form as presented in Fig. 8 can't be used in the plant control system. It was decided to develop therefore model based software for appraisal of combustion process using current and historical data from the SCADA systems.
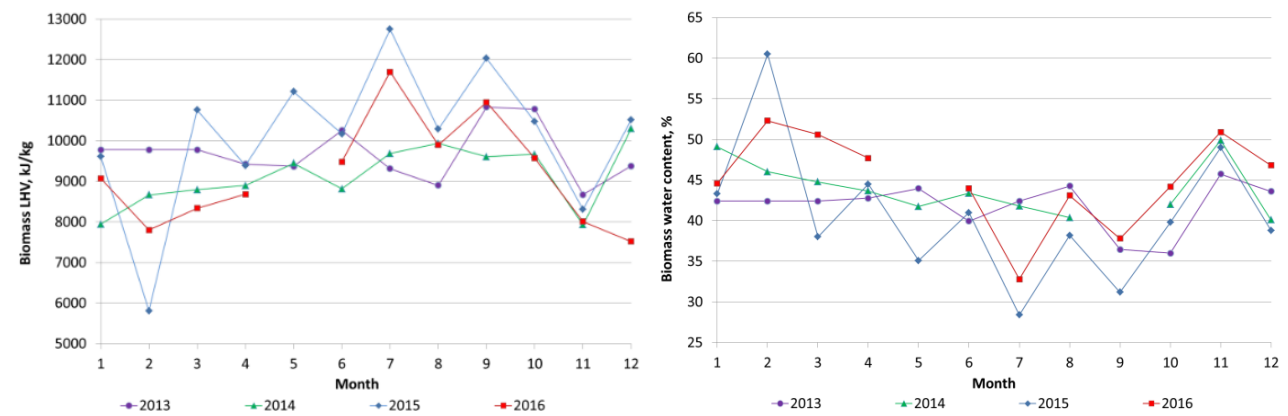

Fig. 8. Biomass heating value and water content at Krosno plant.

Different approach was adopted in the case of Scharnhauser Park. The system has been continuously modernised during the entire period of its exploitation as it was subject to several research projects. Different measurement equipment has been installed such as combustion air flow meters. Within current project the ProcessOPT system [11, 12] developed by the project partner APOS GmbH has been installed. The system allows continuous on-line monitoring of fuel parameters such as LHV, water and ash content. The measured data can be, stored in a database and passed to the boiler control system. The technology is based on the Near Infrared Spectroscopy (NIRS). Biomass components in the NIRS spectro-area provide a reflection or absorption which can be analysed with corresponding mathematical methods. Key element of the system is the Central Spectrometer Unit (CSU) which is an optical measuring device presented in Fig. 9. Values measured by the spectrometer measuring head are further processed using a complex analysis software also developed by APOS Gmbh. Fig. 10 to Fig. 12 show measurement data recorded during 
two sample days of system operation. It can be noted that biomass parameters change on continuous basis and volatility values is significant and dependent on the feedstock delivered to the plant each day. These measurements were used to develop predictive biomass combustion model that will be presented in future work.
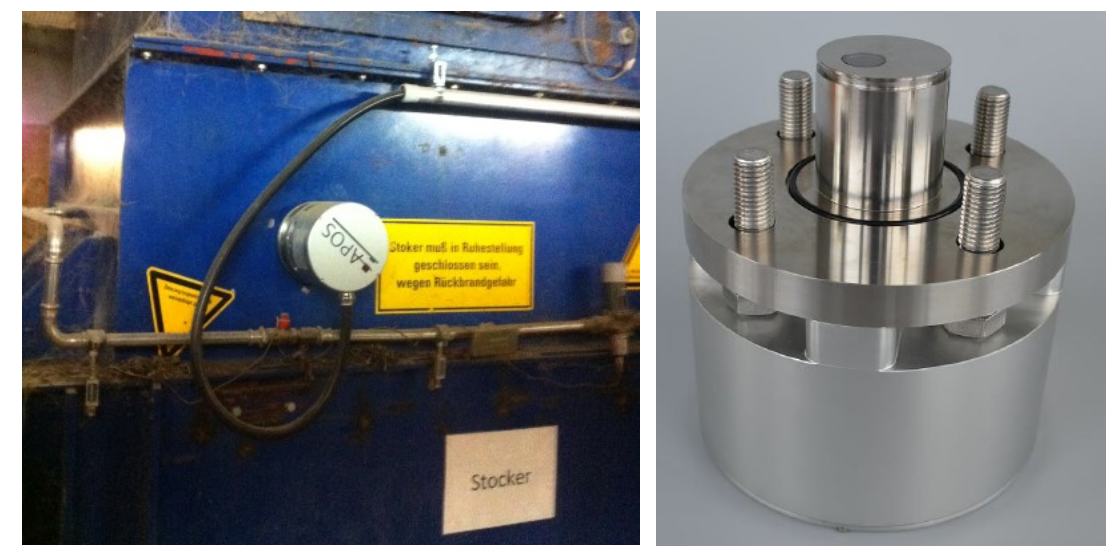

Fig. 9. Measuring head of the Central Spectrometer Unit; installed at biomass hopper at the Scharnhauser Park (left) and naked (right) [12].

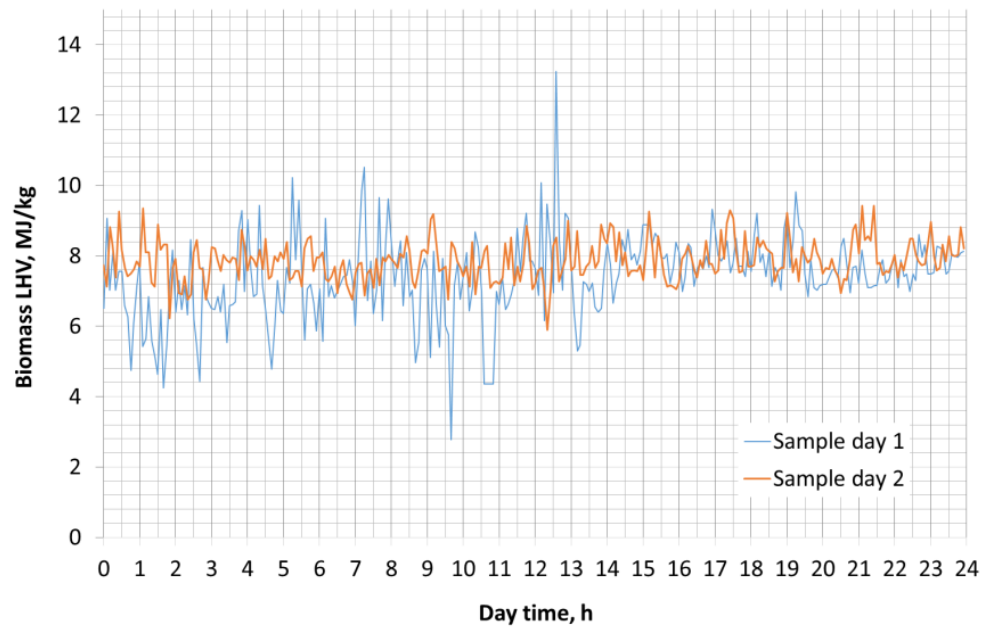

Fig. 10. Results of continuous measurement of biomass heating value. 


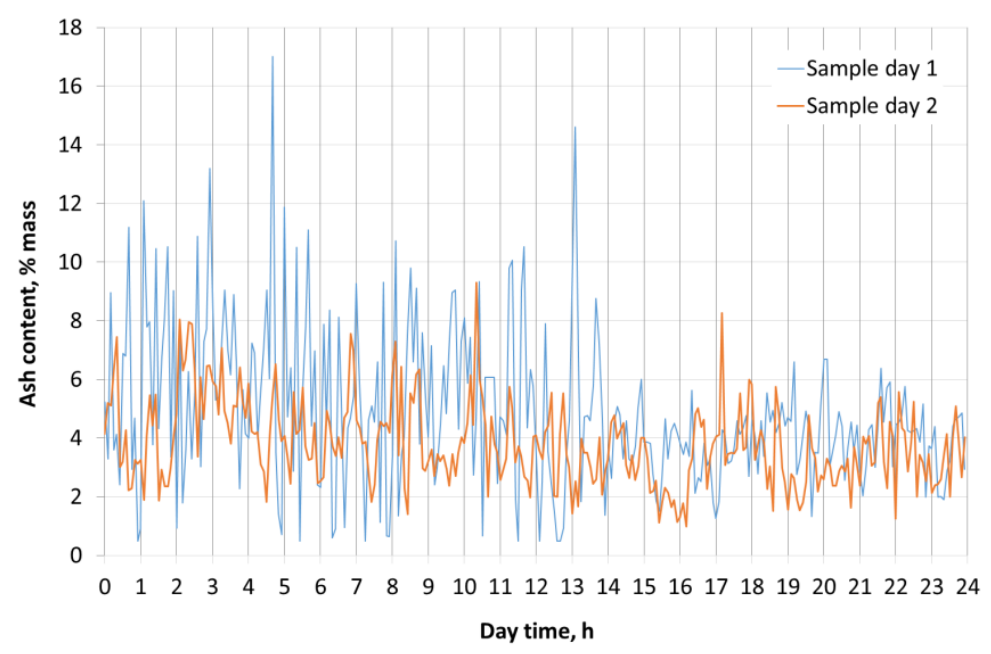

Fig. 11. Results of continuous measurement of biomass mass ash content.

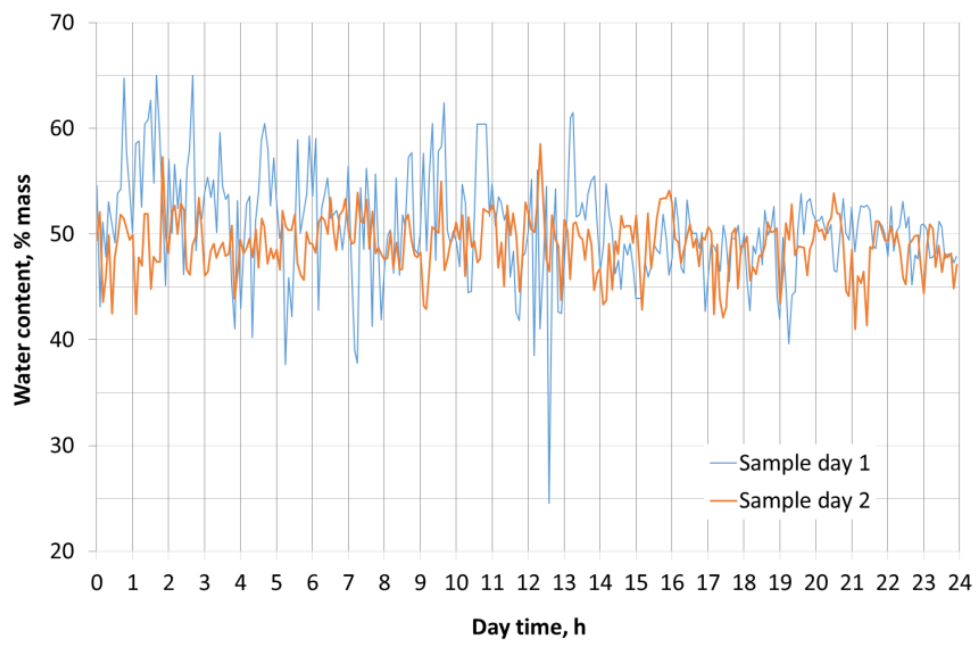

Fig. 12. Results of continuous measurement of biomass mass water content.

\section{Models of biomass combustion}

Described problems and challenges connected with biomass combustions enforced developing of various models for design furnaces as well supporting control of the combustion process. Until design practice is supported mainly by sophisticated CFD modelling, the control systems require simpler and faster models which can be used in real time operation. Several approaches can be find in literature dedicated to various grate combustion [7, 8]. As it was pointed before, also object in Ostfildern has been analysed using model presented in [5]. Based on this experience, two models are proposed for supporting control strategies in presented systems with regards for specific features of each combustion system.

In case of object in Ostfildern, the main aim of the model is utilization of APOS NIRS measurements for smoother boiler operation using low quality biomass. At constant load operation of fluctuations of state parameters are caused mainly by the volatile biomass properties. Therefore it was decided to model the combustion process using simplified 
stoichiometric model based on on-line measurement of feedstock parameters. During different tests it was found that the time required to move a portion of fuel from the point where the NIRS system measuring head is installed is around $\Delta t=60$ minutes at full load.

At the first stage models determines biomass composition using NIRS measurements. At particular time $\mathrm{t}$ measurements from the time step $\mathrm{t}-\Delta \mathrm{t}$ are used. Then composition if found by solving the optimisation problem of find minimum of constrained linear multivariable function in the form:

$$
\left|L H V_{\text {bio }}-L \widehat{H} V_{\text {bio }}\right| \rightarrow \min
$$

where the $L H V_{\text {bio }}$ was calculated using formula for $H H V_{\text {bio }}$ in $\mathrm{MJ} / \mathrm{kg}$ developed by Channivala et al. [7]:

$$
H \widehat{H} V_{b i o}=0.3491 C+1.1783 H+0.1005 S-0.1034 O-0,0151 N-0.0211 a
$$

where: $C, H, S, O, N, a$ - results of ultimate analysis in the form of mass content of carbon, hydrogen, sulphur, oxygen, nitrogen and ash in dry biomass.

From $\mathrm{HH} \mathrm{V}_{\text {bio }}$ lower heating value $\mathrm{L} \widehat{\mathrm{H}} \mathrm{V}_{\text {bio }}$ of biomass as received is calculated using the formula:

$$
L \widehat{H} V_{\text {bio }}=\left(H H V_{b i o}-r \frac{H m o l}{2} M_{H_{2} O}\right)(1-w)-r w
$$

where: $r$ - evaporation enthalpy in $25^{\circ} \mathrm{C}, \mathrm{MJ} / \mathrm{kg}, \mathrm{Hmol}$ molar content of hydrogen, $M_{\mathrm{H}_{2} \mathrm{O}}$ - molar mass of water, $w$ - biomass water content, $\%$.

It was assumed that biomass components are $C, H, S, O, N, C l, a$ and $w$. After studying data collected in the Phylis database [14] the following upper and lower bounds for biomass composition have been established: $34.0 \leq C \leq 52.0 ; 3.0 \leq H \leq 7.0 ; 0.0 \leq S \leq 0.2 ; 34.0 \leq O \leq$ 45.0; $0.03 \leq \mathrm{N} \leq 0.9 ; 0.0 \leq \mathrm{Cl} \leq 0.5$.

The constraint equations is:

$$
\sum_{i} g_{i}=1.0
$$

where $g_{i}$ - mass fractions of biomass components.

After composition of biomass is determined stoichiometric calculations are performed and the value of excess air coefficient $\lambda$ is determined using measurements of oxygen content in the dry exhaust gas [O2]. Then energy balance is performed for assumed value of EGR mass flow fraction. The energy balance equation takes the form:

$$
\begin{aligned}
& \dot{m}_{\text {bio }} L H V_{\text {bio }}+\dot{m}_{a i r} h_{\text {air }}+\dot{m}_{E G R} h_{E G R}= \\
& \dot{m}_{e x} h_{e x}+\dot{m}_{c h a r}\left(L H V_{c h a r}+h_{c h a r}\right)+\dot{m}_{a s h} h_{a s h}+\dot{Q}_{l}
\end{aligned}
$$

where: $\dot{m}_{\text {bio }}, \dot{m}_{\text {air }}, \dot{m}_{c h a r}, \dot{m}_{a s h}, \dot{m}_{E G R}$ - mass flow rates of wet biomass, air, unreacted char, ash and recirculated exhaust gas respectively, $h_{\text {air }}$ - enthalpy of preheated air, $\mathrm{MJ} / \mathrm{kg}$; $h_{c h a r}, h_{a s h}-$ specific enthalpy of char and ash, $L H V_{\text {char }}$ - lower heating value of char, $\mathrm{MJ} / \mathrm{kg} ; \dot{Q}_{l}-$ heat loss, MW.

It was assumed that the lower heating value of char is $30.0 \mathrm{MJ} / \mathrm{kg}$ and its heat capacity is [9] in $\mathrm{J} / \mathrm{kgK}$ :

$$
\begin{aligned}
c_{\text {char }}= & -334.0+4410 * 10^{-3} T-3160 * 10^{-6} T^{2}+1010 * 10^{-9} T^{3}- \\
& 119 * 10^{-12} T^{4}
\end{aligned}
$$


Heat capacity of ash was calculated using formula [10]:

$$
c_{a s h}=0.18+1.4 * 10^{-4} T
$$

Sample results of exhaust gas temperature simulation are presented in Fig.. Data from 1440 minutes of system operation were used in the form of minute average values. Constant value of exhaust gas recirculation ratio equal 0.38 was assumed and temperature at the char combustion zone of the combustion chamber calculated using linear approximation of measured data. As can be noticed results are in good agreement with measured temperature. The average absolute error for 1440 minutes of operation was $19.52 \mathrm{~K}$ and average relative error was $2.1 \%$.

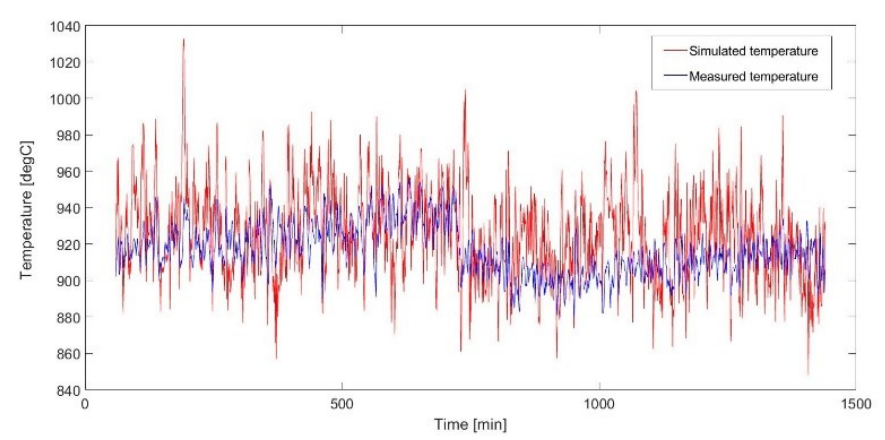

Fig. 13. Results of simulation of combustion chamber outlet gas temperature (T4).

Another situation takes place in case of Krosno cogeneration power plant. The annual average energy efficiency calculated for the Krosno plant is at the level of $\eta_{e l}=0.20$, which is much higher than the theoretical value calculated using technical specification data $\left(\eta_{e l}=0.156\right)$. This is mainly result of overestimation of biomass water content and underestimation of its heating value due to volatility of biomass characteristics. Fig. 1 depicts efficiency of biomass boiler calculated using information on hourly heat production, biomass consumption and available monthly average characteristics of the feedstock from the direct formula:

$$
\eta_{b i o}=\frac{\dot{Q}_{o i l, H T}+\dot{Q}_{o i l, L T}}{\dot{m}_{b i o} L H V_{b i o}}
$$

It can be noticed that unrealistic values higher than $\eta_{b i o}=1.0$ occur. The shape of efficiency curve is also unusual, indicating higher values of efficiency at part load conditions. Therefore it can be concluded that out of the heating season, and especially in summer, biomass is more dry than it results from laboratory tests.

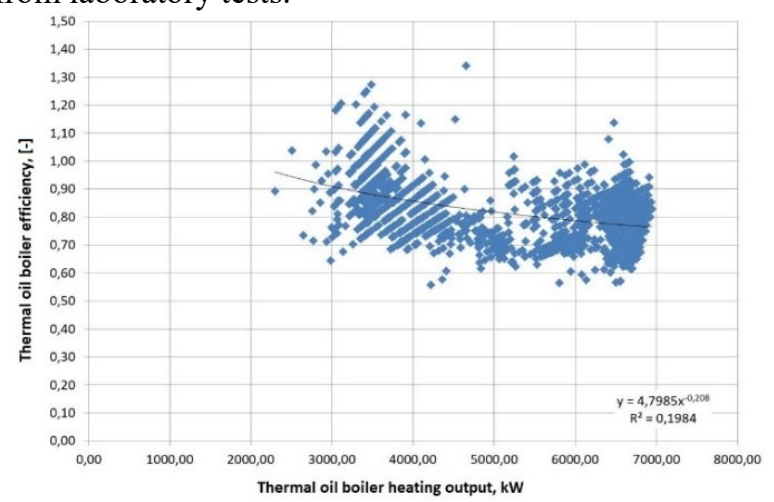

Fig. 1. Approximate efficiency of biomass boiler at Krosno plant according to direct formula (8). 
Therefore firstly the model for operational assessment of the biomass boiler has been developed. It based on available SCADA measurements with assumption that dry fraction of biomass is uniform but its water content, mass flow and heating value are highly uncertain. It was assumed also that the most of thermal parameters of the biomass boiler is stable and possible to identification. Model is derived from three linked energy equations formulated for primary and secondary combustion zones as well for the thermal oil heater:

$$
\begin{gathered}
m_{H 2 O} h_{H 2 O}+m_{\text {pair }} h_{\text {pair }}+m_{\mathrm{EGR}} h_{E G R}+m_{\text {vin }} h_{\text {vin }}+m_{f g 0} h_{f g 0}= \\
m_{f g 1} h_{f g 1}+m_{\text {vout }} h_{\text {vout }}+Q_{\text {grate }}+Q_{\text {wall }} \\
m_{f g 1} h_{f g 1}+m_{\text {vout }} h_{\text {vout }}+m_{\text {sair }} h_{\text {sair }}=m_{f g 2} h_{f g 2}+Q_{\text {wall }} \\
m_{f g 2} h_{f g 2}-m_{f g 3} h_{f g 3}=m_{\text {toin }} h_{\text {toin }}-m_{\text {toout }} h_{\text {toout }}+Q_{l}
\end{gathered}
$$

where: $m_{\mathrm{H} 2 \mathrm{O}} h_{\mathrm{H} 2 \mathrm{O}}$ - mass and specific enthalpy of evaporated water from biomass during time step, $m_{\text {pair }} h_{\text {pair }}, m_{\text {sair }} h_{\text {sair }}-$ mass and specific enthalpy of primary and secondary air, $\mathrm{m}_{\mathrm{EGR}} h_{E G R}-$ mass and specific enthalpy of recirculated exhaust gas, $m_{\text {vin }} h_{\text {vin }}$ $m_{\text {vout }} h_{\text {vout }}$ - mass and specific enthalpy of volatiles released from biomass and transferred to secondary combustion zone, $m_{f g 0} h_{f g 0}$ - mass and specific enthalpy of flue gases released from combustion on grate, $m_{f g 1} h_{f g 1}, m_{f g 2} h_{f g 2}, m_{f g 3} h_{f g 3}$ - mass and specific enthalpy of flue gases transferred after primary combustion zone, after secondary combustion zone and after thermal oil heater, $Q_{\text {grate }}$ - heat transferred to grate bed, $Q_{\text {wall }}-$ heat transferred to walls, $m_{\text {toin }} h_{\text {toin }}, m_{\text {toout }} h_{\text {toout }}$ - mass and specific enthalpy of thermal oil at inlet and outlet of thermal oil heater $Q_{l}$ - heat losses from thermal oil heater.

Stoichiometry, heating values, ash thermal properties are calculated identically as before. Heat fluxes and specific enthalpies are identified based on current temperature measurements of combustion chamber, boiler walls and thermal oil heater. Mass flows are evaluated based on fans volumetric performance and pressure measurements. Energy balances are calculated every $60 \mathrm{~s}$ which corresponds to SCADA system time resolution and final results are averaged for every $30 \mathrm{~min}$ which corresponds to boiler inertia.

\section{Conclusions}

Operation experiences of two similar ORC plats have been presented. Although both systems have similar nominal parameters, they work in different operation conditions caused mainly by differences in biomass fuel and control system. Variable and inaccurately predictable properties of biomass raise main problems in control and operation of both systems therefore computational models have been proposed for supporting control systems of them. The results revealed that although biomass combustion process is very complex the simplified stoichiometric model supported with relevant online measurements is able to predict combustion temperature with a satisfactory accuracy.

It should be noted at the real system is never in steady state conditions due to volatility of external parameters, heat accumulation and operation of PID controllers. Therefore the presented models is significant simplification of the real system. However, in more complex models many parameters are not know for industrial objects and therefore reasonable assumptions are required and process identification techniques must be applied. 
This work was carried out within the framework of the Polish - German Sustainability Research Programme STAIR in research project IntBioCHP titled: System integration of biomass fired cogeneration plants. The project is financed by German Federal Ministry of Education and Research and Polish Ministry of Science and Higher Education.

\section{References}

1. EUROSTAT Statistics Explained. Online publication series. Renewable energy statistics.http://ec.europa.eu/eurostat/statistics-

explained/index.php/Renewable_energy_statistics; <last access: 04.05.2018>

2. T. Tartière: ORC Market: A World Overview. Web project available at http://orc-world-map.org/analysis.html <last access: 04.05.2018>

3. T. Tartière, M. Astolfi: A World Overview of the Organic Rankine Cycle Market. Proceedings of the IV International Seminar on ORC Power Systems, ORC2017, 13-15 September 2017, Milano, Italy. Energy Procedia 129 (2017), pp. 2-9.

4. T. Erhart, R. Strzałka, U. Eicker, D. Infield: Performance Analysis of a Biomass ORC Poly-generation System. Proceedings of the 2nd European Conference on Polygeneration, $30^{\text {th }}$ March-1 ${ }^{\text {st }}$ April, 2011, Tarragona, Spain.

5. R. Strzalka, T.G. Erhart, U. Eicker: Analysis and optimization of a cogeneration system based on biomass combustion. Applied Thermal Engineering 50 (2013), pp. 1418-1426.

6. D. Prado, M. Renzi, A. Gasparella, M. Baratieri, Monitoring of the energy performance of a district heating CHP plant based on biomass boiler and ORC generator. Applied Thermal Egineering, Volume 79 (2015), pp. 98-107.

7. R. Bauer, M. Gölles, T. Bruner, N. Dourdoumas, I. Obernberger, Modeling of grate combustion in a medium scale biomass furnace for control purposes. Biomass and Bioenergy 34 (2010), pp. 417-427.

8. A. Boriouchkine, S.L. Jamsa-Jounela: Simplification of a Mechanistic Model of Biomass Combustion for On-Line Computations. Energies 9 (2016), pp. 735.

9. S.A. Channivala, P.P. Parikh: A unified correlation for estimating HHV of solid, liquid and gaseous fuels. Fuel 81 (2002), pp. 1051 - 1063.

10. H. Thunman, F. Niklasson, F. Johnsson, B. Leckner: Composition of Volatile Gases and Thermochemical Properties of Wood for Modeling of Fixed or Fluidized Beds. Energy \& Fuels 15 (2001), 1488-1497.

11. N.Y. Kirov: Specific Heath and Total Contents of Coals and Related Materials At Elevated Temperatures. BCURA Monthly Bulletin 1965, pp. 29 - 33.

12. APOS GmbH: Kontaktmesskopf. Technische Zeichnung. APOS GmbH, Am Marienhof 4, 22880 Wedel, Germany, 2014. http://www.apos.biz/

13. APOS GmbH: Handbuch. CSU - Central Spectrometer Unit. Revision 3.0. APOS GmbH. Optische online und atline Mess- und Regelsysteme. Am Marienhof 4, D-22880 Wedel, Germany, 2014. http://www.apos.biz/

14. Phylis Database (http://www.ecn.nl/phyllis/) 